Highlights

\title{
Self-selection and attrition biases in app-based persuasive technologies for mobility behavior change: Evidence from a Swiss case study
}

Francesca Cellina,Giuseppe Vittucci Marzetti,Marco Gui

- App-based persuasive technologies for behavior change are increasingly exploited to promote sustainable mobility

- Self-selection and attrition due to the opt-in framework may affect their actual impact and bias the estimate of this impact

- We analyze mobility data collected in an app-based behavior change intervention run in Southern Switzerland

- Comparison with census mobility data of the reference population and analysis of app use over time show no evidence of critical biases

- Further research is worth analyzing the app's actual impact and the reasons for the observed high drop-out rate 


\title{
Self-selection and attrition biases in app-based persuasive technologies for mobility behavior change: Evidence from a Swiss case study
}

\author{
Francesca Cellina ${ }^{a, b}$, Giuseppe Vittucci Marzetti ${ }^{a, *}$ and Marco Gui ${ }^{a}$ \\ ${ }^{a}$ Department of Sociology and Social Research, University of Milano-Bicocca, via Bicocca degli Arcimboldi 8, 20126 Milan, Italy \\ ${ }^{b}$ University of Applied Sciences and Arts of Southern Switzerland (SUPSI), Campus Trevano, 6952 Canobbio, Switzerland
}

\section{ARTICLE INFO}

\section{Keywords:}

Persuasive technology

Mobility behavior

Self-selection

Attrition

App churn

Behavior change

\begin{abstract}
A B S T R ACT
App-based persuasive technologies emerged as promising tools to promote sustainable travel behavior. However, the opt-in, self-selection framework characterizing their use in real-life conditions might actually lead to wrongly estimate their potential and actual impact in analyses that do not rely on strict randomized controlled trials. To investigate evidence of such biases, we analyze mobility data gathered from users of a persuasive app promoting public transport and active mobility launched in 2018 in Bellinzona (Switzerland). We consider the users' baseline mobility data: km per day (total and by car) traveled during the app validation period, when behavior change motivational features were not enabled. To estimate the possible self-selection bias, we compare these data with the reference population, using data from the Swiss Mobility and Transport Census; to study the possible attrition bias, we look at the relations between baseline mobility and the number of weeks of app's active use. We find evidence of neither self-selection nor critical attrition biases. This strengthens findings by earlier non RCT-based analyses and confirms the relevance of app-based persuasive technologies for mobility behavior change.
\end{abstract}

\section{Introduction}

The need for a radical change in the mobility system has long been acknowledged (Banister, 2008; Holden et al., 2020). A substantial body of research is investigating how to address the 'automobility' regime (Urry, 2004) and the automobile dependence (Newman and Kenworthy, 1999) in order to support the transition to low-carbon mobility systems and achieve international climate protection goals. Reducing car dependence and favoring sustainable mobility require a variety of complementary policy tools, capable of producing a radical socio-technical transition in current consumption patterns: technology improvement, infrastructure provision, land-use planning, command-and-control regulations, Pigouvian taxes and market-based instruments, as well as cognitive and motivational tools, such as social marketing and nudging. In fact, the current mobility regime is not simply shaped by individual attitudes and consequent choices (Shove, 2010), but it is the outcome of a complex system of provisions, shaped by the interaction between institutions, infrastructure, and daily life practices, reciprocally strengthening each other and reinforcing car use (Cairns et al., 2014; Mattioli et al., 2020).

While fully acknowledging the limited impact of calls for individual behavior change alone, behavior change policies can however act as leverages helping to build individual and collective commitment towards change (O'Brien, 2015; Amel et al., 2017). They can stimulate individuals to collective action and political agency, activating them to call for a

\footnotetext{
*Corresponding author

@ francesca.cellina@supsi.ch (F. Cellina); giuseppe.vittucci@unimib.it (G. Vittucci Marzetti); marco.gui@unimib.it (M. Gui)

ORCID(s): $0000-0003-4425-4750$ (F. Cellina); $0000-0003-3093-8000$ (G. Vittucci Marzetti); 0000-0003-2411-999x (M. Gui)
}

wider action by institutions. Eventually, these policies can steer a socio-technical transformation in the systems of provisions behind car use and favor the social shaping of new shared, cultural meanings around mobility.

Since Fogg's (1998; 2003) seminal contributions, who introduced the concept of persuasive technology within the framework of a new discipline he named 'captology' (the study of Computers As Persuasive Technologies), a growing body of literature is studying the effects of coupling Information and Communication Technology (ICT) with behavior change persuasion techniques. Fogg (1998) defines persuasive computers as interactive technologies that "attempt to shape, reinforce, or change behaviors, feelings, or thoughts about an issue, object, or action" (p.225). Some authors refer to the strictly related concept of behavior change support system (BCSS) introduced by Oinas-Kukkonen (2013), which indicates any "sociotechnical information system with psychological and behavioral outcomes designed to form, alter or reinforce attitudes, behaviors or an act of complying without using coercion or deception" (p. 1225). In this paper, we refer to Fogg's (1998) original definition.

Persuasive technologies usually exploit a combination of persuasive techniques, which have many points in common with the nudging approach (Sunstein, 2014). In fact, the most commonly used techniques are: providing feedback on consequences of individual choices (e.g. the impact on energy consumption or $\mathrm{CO}_{2}$ emissions); inviting to define personal goals for change or engage in individual or collective challenges (competition or collaboration); comparing performances within the virtual communities of users of the same software (social comparison through leader-boards); rewarding through virtual elements (badges or notification messages) or tangible prizes (collection of points to be redeemed by prizes). Such techniques frequently adopt game 
elements in non-gaming contexts, a phenomenon commonly referred to as gamification (Deterding et al., 2011; Hamari et al., 2015; Hamari, 2017).

According to self-determination theory (Deci and Ryan, 2008), the above persuasive elements would act as 'extrinsic motivational factors'. In particular, following Ryan and Deci's (2000) classification of extrinsic motivational factors, that further distinguishes between 'external regulation' (extrinsic rewards and punishments with low motivational effects) and 'integrated regulation' (hierarchical synthesis of goals, having comparable motivational effect as intrinsic factors), depending on the level of self-determination of individual actions, most persuasive technologies rely on external regulation (tangible prizes such as vouchers or discounts for local shops and services), coupling them with integrated regulation (e.g. individual goal setting or the creation of a feeling of a community between their users, by prompting collaboration activities between their members). Following the motivation crowding theory (Frey and Jegen, 2001), use of such extrinsic motivational factors, and particularly of tangible prizes, would support an increase in the individuals' intrinsic motivation and self-determination to change, provided that the individuals perceive them as 'supportive' (they foster their self-esteem and at the same time strengthen their perception of freedom to act), instead of 'controlling'.

Persuasive technologies tackling urban mobility issues and supporting the transition to low-carbon mobility have been increasingly developed in smart city programs (Cocchia, 2014; Silva et al., 2018). Indeed, most of the cities that embrace the smart city framework focus on addressing environmental and mobility issues (Manville et al., 2014; Neirotti et al., 2014). In particular, the diffusion of ICTs favored the implementation of 'soft' transport policy measures, sometimes also referred to as Voluntary Travel Behavior Change (VTBC) initiatives, i.e. policy measures aimed at producing voluntary changes in car use by means of cognitivemotivation tools (Steg and Tertoolen, 1999; Cairns et al., 2008; Chatterjee and Bonsall, 2009; Bamberg et al., 2011; di Teulada and Meloni, 2016; Gössling, 2018).

Thanks to the diffusion of GPS devices and their embedding into smartphones, that are increasingly equipped with a growing number of additional sensors, on-purpose developed smartphone apps emerged as particularly suitable tools to automatically collect large-scale and fine-grained mobility data (Vlassenroot et al., 2015; Gadziński, 2018) and support mobility behavior change interventions, such as promoting alternative route or departure time choices, or supporting modal shift (Zhao and Baird, 2014; Tsirimpa et al., 2019; Hu et al., 2020). On the one hand, they provide citizens with real time feedback and other motivational elements prompting their behavior change; on the other hand, the collected data on citizens' mobility patterns can be used to shape urban policies and plans (Weber et al., 2018).

A number of cities have already adopted app-based persuasive technologies and integrated them within their urban mobility policies; for example, Bologna in Italy, with the Bella Mossa platform, or a number of cities in Spain, that
Table 1

Persuasive apps aimed at reducing car use at the urban level

\begin{tabular}{lll}
\hline Year App & Country & References \\
\hline 2009 UbiGreen & USA & Froehlich et al. (2009) \\
2012 Tripzoom & Netherlands & Bie et al. (2012) \\
2013 Matkahupi & Finland & Jylhä et al. (2013) \\
2014 IPET & Italy & Piras et al. (2018) \\
Peacox & Ireland & Bothos et al. (2014) \\
2015 BetterPoints UK & Bowden and Hellen (2019) \\
QT & USA & Jariyasunant et al. (2015) \\
TrafficO2 & Italy & Di Dio et al. (2018) \\
2016 GoEco! & Switzerland Cellina et al. (2019) \\
Play\&Go & Italy & Kazhamiakin et al. (2021) \\
2017 Bellamossa & Italy & Bowden and Hellen (2019) \\
Ciclogreen & Spain & Campos-Sánchez et al. (2019) \\
SMART & Netherlands Huang et al. (2018) \\
2018 Bellidea & Switzerland Cellina et al. (2020) \\
OPTIMUM & Austria, UK Tsirimpa et al. (2019) \\
\hline
\end{tabular}

rely on crowdsourced data collected through the Ciclogreen app to improve land and transport planning decision-making processes (Table 1). Such apps usually aim at replacing car use at the urban level with more sustainable transport modes (cycling, walking and public transport), and they mostly build on tangible rewards: the more the kilometers one travels by sustainable transport, the more the points she gets, which can later be redeemed for real-life prizes. ${ }^{1}$

Although analyses on their use in real life conditions, presented in the literature cited in Table 1, provide evidence of their behavior change impact, which favored their diffusion and adoption as policy tools for urban mobility, research is still needed to assess their actual impact in bringing about tangible effects in reducing car use. Meta-analyses have in fact shown that the above evidence is at least controversial, demanding for more scientific rigor in the assessment of the impacts (Hamari et al., 2014; Shaheen et al., 2016, 2017; Sunio and Schmöcker, 2017; Vlahogianni and Barmpounakis, 2017; Anagnostopoulou et al., 2018; Andersson et al., 2018).

Evidence-based policy-making would in fact require to perform randomized controlled trials (RCTs) in order to reliably assess the effectiveness of these tools, as for instance remarked by Graham-Rowe et al. (2011) and Arnott et al. (2014) regarding soft transport policy measures. However, as stressed among the others by Bhushan et al. (2018) about energy saving behavior change programs, strict RCTs are seldom feasible. Performing them would in fact require to overcome a number of relevant practical challenges (Cellina et al., 2019), such as for instance how to guarantee mobility data collection for a control group of users without biases due to the Hawthorne effect (Gillespie, 1991), or a

\footnotetext{
${ }^{1}$ Even though these apps are seldom explicitly grounded in a behavior change theory, they can be related to the norm-activation model (Schwartz, 1977; Schwartz and Howard, 1981), the theory of planned behavior (Ajzen, 1991), or models of change as a process through stages, such as the transtheoretical model of behavior change (Prochaska and Velicer, 1997) or the stage model of self-regulated behavior change (Bamberg, 2013).
} 
sufficiently long data collection period for both control and treatment groups. More critically, RCTs would require the random selection of individuals participating in the trial, followed by their random assignment to treatment and control. As a matter of fact, however, in most of the cases neither researchers nor city authorities can randomly select citizens and impose them to use a persuasive app for a given period of time. Most of the research interventions aimed at assessing the impact of persuasive apps, therefore, can only be performed within voluntary, opt-in, self-selection frameworks, which seriously challenges random selection and assignment. From the point of view of policy-making, therefore, it becomes relevant to explore presence of self-selection and attrition biases, which may arise in such a framework.

In particular, in typical interventions app users are recruited through open communication campaigns targeting the general public, and this is at risk of mostly raising the interest of individuals already using public transport and active mobility (walking and cycling). A risk of 'preaching to the converted' has in fact emerged in app-based persuasive interventions targeting energy and water-saving consumption patterns (Wemyss et al., 2018; Tiefenbeck et al., 2019) and, in general, it characterizes any voluntary opt-in policy programs, where target groups are free to comply with the policy. If so, the population of 'mainstream car drivers', namely the actual app's and intervention's target group, would simply ignore the campaigns and consequently be excluded from the intervention. If app users were systematically different than the app's actual target group, usually corresponding to the reference population, a self-selection bias (Heckman, 1990) would occur. More precisely, if app users were more likely to be individuals having already reduced their car use in favor of public transport and active mobility, the behavior change impacts associated to the intervention in empirical studies not based on strict RCTs would in fact be over-estimated, whereas the actual impacts would be lower than expected.

Another element can further weaken the evidence by the earlier estimates of behavior change impact. The voluntary, opt-in, self-selection framework characterizing interventions also allows app users to drop app use whenever they like. Hence, app-based persuasive interventions on the field are also affected by attrition. If such an attrition does not happen at random and 'early dropout' app users are systematically different in some of their mobility characteristics compared to 'loyal' app users, an attrition bias occurs (Hausman and Wise, 1979). In particular, if loyal app users were individuals already adopting more sustainable mobility behavior than early drop-out users, the impact of the app over time in empirical studies that do not include individual fixed effects would be overestimated. Moreover, if the same individuals that are already adopting sustainable mobility practices had small scope for further improvements, in fixed-effects panel data models that do not properly account for attrition, the same impact would be underestimated. Policy-wise, detecting possible attrition biases is therefore relevant as well. Particularly, identifying a lack of attrition biases would further strengthen the behavior change findings by earlier research interventions, thus confirming the effectiveness of smart city initiative promoting persuasive technologies in the mobility domain.

Against this background, the aim of this paper is to assess the presence and extent of self-selection and attrition biases in the analyses based non RCT-based interventions. We consider a case study in the Swiss city of Bellinzona (capital of Canton Ticino, located in the Southern, Italian-speaking part of Switzerland) and take advantage of the Bellidea 'transition experiment', launched in 2017 by the city and aimed at persuading more sustainable mobility patterns through the Bellide $a$ behavior change app. This case is suitable, since, in an initial validation period (two weeks), data on the mobility patterns of the app users (kilometers traveled per day, total and by car) were collected by the app itself, while the app motivational features were not enabled. These data can be regarded as the 'baseline mobility patterns' of the app users, i.e. their mobility patterns before they start being persuaded by the app. By comparing these baseline mobility data with the mobility data of the reference population from the Swiss Mobility and Transport Census (SMTC), we investigate the presence and extent of self-selection bias. By analyzing the relations between the baseline mobility of app users and their number of weeks of active app use, we investigate the presence and extent of attrition bias.

The paper is organized as follows. Section 2 introduces the material used in this analysis, namely the behavior change process launched by the city of Bellinzona and the features of the related persuasive app; then, it describes the method followed in order to analyze the mobility patterns of app users and investigate the presence and extent of self-selection and attrition biases. Section 3 presents the results on the analyses of the mobility patterns of the app users. Section 4 discusses them, dealing with measurement error, drop-out rates after registration, and external validity. Section 5 concludes by providing recommendations and possible venues for future research.

\section{Methods and data}

In the Swiss city of Bellinzona (around 45'000 inhabitants), car is the dominant transport mode. In the region of Canton Ticino, car dependence is definitely higher than other Swiss regions, as indicated by the normalized motorization rate (the number of passenger cars per 1'000 inhabitants) reported in Figure 1.

Since the relevant investments for new cycling infrastructures and improved bus/train inter-changes undertaken by city authorities in the recent past were not sufficient to significantly reduce car use, city policy-makers opted for exploring different ways to address the issue. Thus, they launched a transition experiment, i.e. an innovation project aimed at solving persistent societal problems, that takes place in real-world settings and builds on the collaboration between different societal actors, all committed to transformational change (Van den Bosch, 2010; Luederitz et al., 2017; Sengers et al., 2019). City managers of Bellinzona decided in fact to create a persuasive app promoting bicycle, walking, 
Self-selection and attrition biases in app-based persuasive technologies

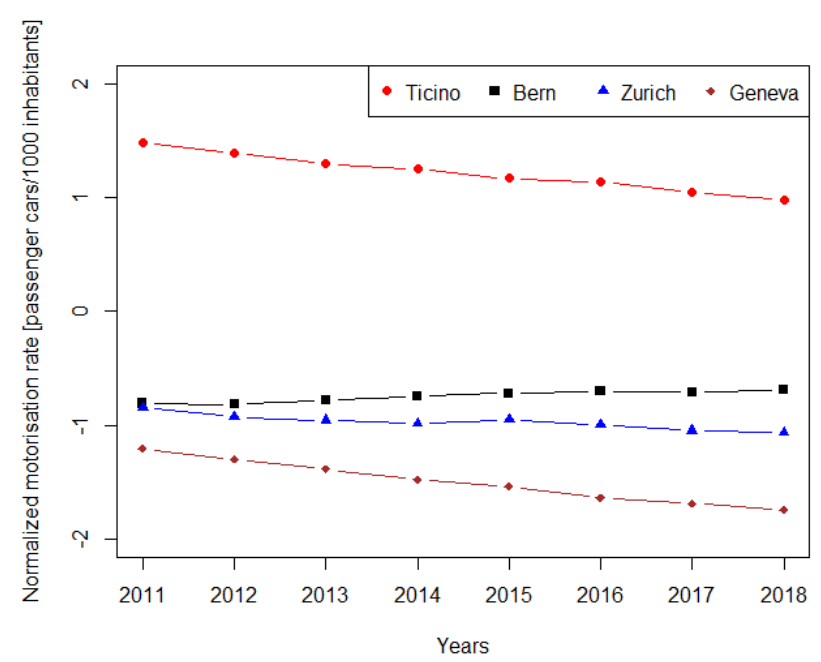

Source: Our elaboration on data from the Swiss Federal Office for Statistics (z-scores computed on the yearly mean and standard deviations of observations for all Swiss Cantons).

Figure 1: Standard scores of motorization rates in a selection of Swiss Cantons (2011-2018)

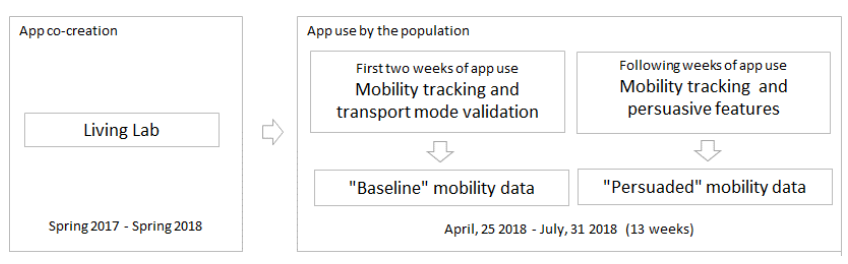

Figure 2: The process of the Bellidea transition experiment

and public transport, to be made freely available to the whole population among the city's transport policy measures. Instead of relying on an expert-driven approach and charging external private companies with the development of the app, they opted for a participatory process and for opening up the creation of the app features and contents to any interested citizen, within a 'living lab' process (Pallot et al., 2010; Almirall et al., 2012; Dell'Era and Landoni, 2014). Living labs are increasingly exploited in transition experiments for sustainability, since they allow to offer opportunities for broad stakeholder engagement, co-creation, and collective learning (Nevens et al., 2013). They can be described as processes aimed at creating and validating innovation within collaborative, real-world environments, by involving a broad range of stakeholders. Differently than expert-driven processes, living labs see users as active partners of the value creation process (Sanders, 2002; Sanders and Stappers, 2008).

The transition experiment, whose process is schematized in Figure 2, was called Bellidea. The living lab aimed at app co-creation was launched in Spring 2017, in partnership with the local university of applied sciences and Provelo, a local NGO for the promotion of bicycle use. Citizens were recruited by a campaign aimed at engaging a sufficiently wide and diversified group of participants. Both bottom-up and top-down recruitment activities were performed: communi- cations on local media, including social media, was aimed at allowing any interested citizens to join lab activities. Furthermore, direct contacts by the City of Bellinzona with relevant associations and institutions, identified through a stakeholder analysis based on the methodology proposed by Reed et al. (2009), allowed to guarantee a balanced composition of the participants between 'converted' users of public transport and active mobility and 'mainstream car drivers'. The result was a group of around thirty volunteers, who regularly met once a month from March 2017 to February 2018. During first living lab meetings they tested already existing apps and discussed their features. Later meetings were instead shaped as co-creation workshops: by interacting with app paper prototypes (wireframes), they identified the key features of the new app. Final meetings were used as test-beds for the app prototype.

At the end of April 2018, the Bellidea app was ready to be launched to the whole population of Bellinzona, among the set of municipal policy tools to address local mobilityrelated challenges. The launch was performed through a press conference by the City of Bellinzona on April, 252018 , followed by a number of communications on local newspapers, weekly magazines, radio and television programs ${ }^{2}$, with the aim of raising the interest of the general public as potential app users, specifically targeting the 'mainstream car drivers'. No specific communications were arranged targeting specific subgroups of the population, such as for instance bicycle or public transport users - which reassures us on the absence of prior biases affecting the spontaneous process of recruitment of app users and the self-selection framework characterizing app use. From the launch onward, any interested citizens living, studying or working in Bellinzona could download and start using Bellidea whenever they liked. Overall, the Bellidea app was active for 13 consecutive weeks, until the end of July 2018. Data collected by app users during such a period of free app availability to any interested citizens provide us with the basis for testing the presence of self-selection bias in response to the launch of the app to the whole population.

Once installed on the smartphone, the app was always active in background and performed automatic tracking of the traveled activities and routes and identification of the transport modes, providing users with eco-feedback on their mobility patterns (travel time and distances, energy consumption and $\mathrm{CO}_{2}$ emissions) and inviting them to collect points, to be redeemed for real-life prizes. Figure 3 shows a selection of screenshots of the Bellidea app (only available in the Italian language). Points were attributed on a weekly basis, depending on how users moved: the higher the weekly percentage of traveling time by low carbon and low energy consumption transport modes (public transport, bicycle or walking), the higher the amount of obtained points. Namely, differently than the dominant approach that attributes points based on the amount of kilometers traveled by a given set of

\footnotetext{
${ }^{2}$ The full Bellidea press review materials (in Italian) are available on the Bellidea website at http://www. bellidea.ch/documenti or upon request to the authors.
} 


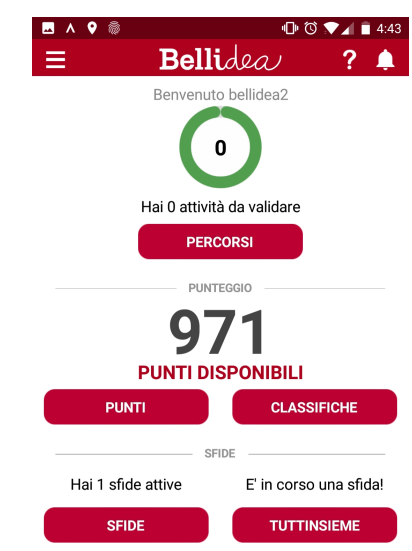

a.
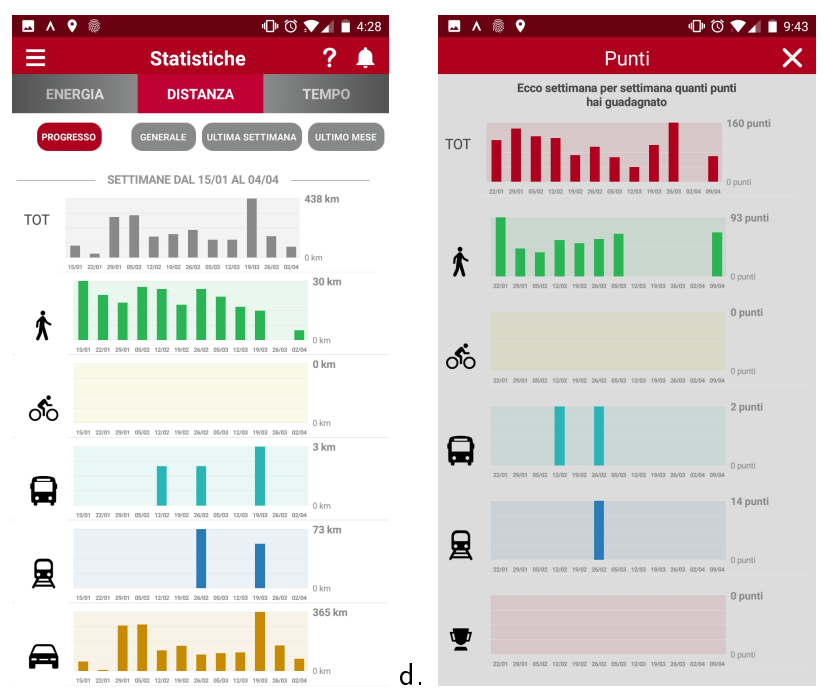

Figure 3: A selection of screenshots of the Bellidea app: a) the landing page, showing available points; b) the trip validation feature; the weekly feedback statistics: c) evolution over time of travel distances; d) points

transport modes, Bellidea attributed points based on one's weekly mobility patterns as a whole, by accounting for all the kilometers traveled and all the transport modes used, and by considering the percentage of low carbon transport modes. Removing the effect of the weekly travel distance, the point attribution mechanics leveled off users regarding their possibility to get points: independently on their weekly travel distance, each user could theoretically be rewarded with the maximum available amount of weekly points. Additional points could be obtained by joining and successfully completing individual and collective challenges for change. Points allowed for a comparison between the users, by means of a weekly leader-board, and could be exchanged for prizes such as discounts on energy bills, local organic honey, and/or leisure activities (cinema, theater, museum, swimming pool, etc.), or public transport tickets. Prizes were directly selected and offered by the City of Bellinzona and a few public partners, such as the local public transport operator and utility company.

Following a general approach also suggested by Welsh et al. (2014), and specifically the methodology and tools proposed by Bucher et al. (2019), Bellidea relied on an already existing activity tracking app named Moves (now discontinued), which tracked all basic mobility data, organized them in 'routes' and 'activities' (segments of a route that are travelled by the same transport mode), and automatically detected the transport mode used for each activity (walking, cycling and general 'motorized transport'). Data collected by Moves where then automatically accessed by Bellidea, which then processed them by an on-purpose developed random decision forest algorithm, to further classify the "motorized transport' mode. All the above process was completely transparent to the user, who was simply requested to initially also download the Moves app and connect it with Bellidea, by agreeing on the app's Terms and Conditions. After that, she could forget about Moves and only interact with Bellidea. As a result, for each activity, Bellidea was able to infer the probability of having been traveled by one of the following transport means: walking, cycling, train, bus, car, and other. Then, the transport mean with the highest probability was selected and used in the feedback and gamification features of the app. The overall accuracy of this operation was rather high (on average, $87 \%$ of the transport modes were correctly identified), as long as users initially provided ground-truth data for a sufficient number of activities to train the underlying algorithm. In fact, even though a general algorithm training had been performed before the app release, specific training aimed at improving accuracy by learning the mobility patterns of each new user was performed within the app itself, through the feature of 'validation' of the detected transport mode. Validation was compulsory for the first 80 collected activities. Such a threshold was identified based on the data collected by the Living Lab participants when interacting with the Bellidea app prototype during the testing phase (6'047 validated activities collected by 28 voluntary lab participants between January, 15 and March, 11 2018). On average, 80 activities corresponded to two weeks of app use. After such a period, instead, validation was no longer allowed, in order to avoid that, wishing to collect more points, users cheated the system by selecting different means of transport for the activities they had actually traveled by car.

During the initial two-week validation period, none of the persuasive features of Bellidea were enabled: the app just performed mobility data collection and no feedback, challenges, points, or prizes were attributed. Since users were requested to validate all their activities, data collected during this period can be reasonably considered as the users' baseline mobility data. Namely, they can be treated as a reliable observation of the mobility patterns of app users, before the app started affecting their mobility behavior.

Raw data were collected at the level of the single activity, namely the segment of a route that is traveled with a single mean of transport. All such data were saved in the 
Bellidea database, hosted on servers run and managed by the utility company of the city of Bellinzona. At the end of the 13 weeks of app use, we were provided with an extraction of data from this data-base, reporting the mobility data collected for each app user, aggregated at the week level, under signature of a confidentiality agreement with the City of Bellinzona.

For the analyses in this paper, the following data extracted from the Bellidea database are exploited: i) the mobility data collected during the first two weeks of app use by each user, for each travel activity (travel distance in kilometers and user-validated means of transport). Particularly, to characterize the baseline mobility behavior of each app user, we compute the following variables: overall travel kilometers per day and travel kilometers by car per day. Among the different transport modes used, we specifically focus on car travel since the final aim of the Bellidea app was to reduce car use. Car travel-related variables are therefore key in order to both assess the app's impact and also to discriminate between 'mainstream car drivers' and 'already converted' users; ii) the number of 'active weeks' for each user, namely the number of weeks for which, out of the 13 weeks of app availability, mobility data were collected. For each user, a week is considered 'active' if at least four activities are available in the Bellidea database.

To estimate the possible self-selection bias, the Bellidea baselines are compared with the mobility statistics for Bellinzona using the data taken from the 2015 Swiss Mobility and Transport Census (SMTC), a national survey performed every 5 years across Switzerland aimed at knowing the population's transport behavior (Office fédéral de la statistique, 2017, 2018). ${ }^{3}$ This comparison allows to test whether Bellidea users can be best labeled as 'mainstream car drivers' or as 'already converted' individuals having reduced car use in favor of public transport and active mobility. In the latter case, the mean of the Bellidea individual baselines (overall daily travel distance and daily travel distance by car) would be significantly lower than the SMTC data. This could lead to overestimate the actual impact in empirical analysis which does not rely on thorough RCTs based on randomly selected samples of app users.

Such a comparison fails to account for another phenomenon that usually characterizes innovation diffusion, as well as any voluntary adoption process with no obligation to comply: high dropout rates after relatively short periods of interaction with the innovation. The difficulty of retaining individuals' interest for long periods of time is widely acknowledged in attempts to promote individual behavior change by means of voluntary interventions in real life, since it simply depends on the level of individual intrinsic motivation (Bonsall, 2009; Stopher et al., 2009). In panel studies and RCTs, this phenomenon is dealt with under the concept of attrition,

\footnotetext{
${ }^{3}$ Although these data refer to different years (2015 and 2018, respectively), differences in the distribution of mobility patterns of population between the two years are expected to be negligible, since no relevant interventions affecting car use were introduced (neither regulations, incentives or taxation schemes nor the provision of new infrastructures or different traffic management plans).
}

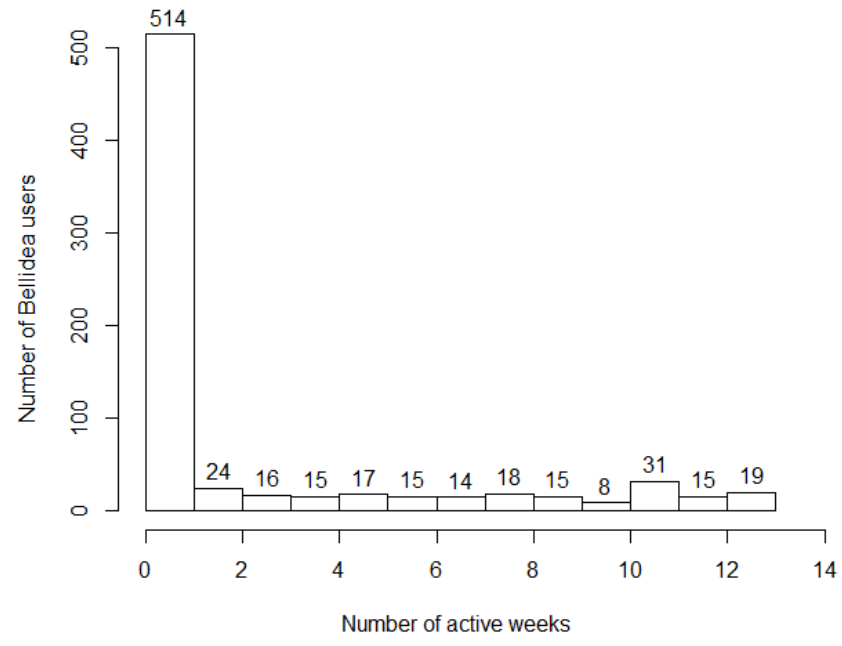

Figure 4: Distribution of the Bellidea app users by active weeks

while in the world of apps and games it is usually dealt with under the 'app churn' concept (Hadiji et al., 2014; Periáñez et al., 2016). Independently on the reasons for app churn on the Bellidea app users, which would need a dedicated research design, we aim at gaining insights on the implications of this phenomenon on the emergence of an attrition bias. To this purpose, we investigate if there is evidence of any statistical dependence between the baseline mobility of app users and their number of active weeks. In case 'mainstream car drivers' were more likely to drop app use earlier than 'already converted' app users, the mean of users' travel kilometers per day (total and by car) conditional on the number of active weeks would negatively depend on the number of active weeks. If so, app churn could reduce the app potential impact and result in an attrition bias leading to overestimate or underestimate the app's actual impact in empirical analysis not properly accounting for the phenomenon of attrition.

\section{Results}

Throughout the 13-week period of free availability of the Bellidea app to any interested citizens, overall 721 user accounts were registered. As shown in Figure 4, most of such users however only downloaded the app for curiosity and did not interact with it for a sufficiently long period of time to unlock the app persuasive features. Namely, they did not complete the initial two-week period aimed at training the automatic transport mode detection algorithms. Mobility baseline data are therefore only available for the $n=207$ users for which at least two active weeks of mobility data are available. The following analyses focus on these users.

As discussed in the previous section, to investigate the possible self-selection bias, the mobility baselines of Bellidea users are compared with the 2015 SMTC mobility data available for Bellinzona $(n=564)$. Figure 5 shows the box plots (without outside values) of the total daily travel distance (total kilometers per day, top) and daily travel dis- 

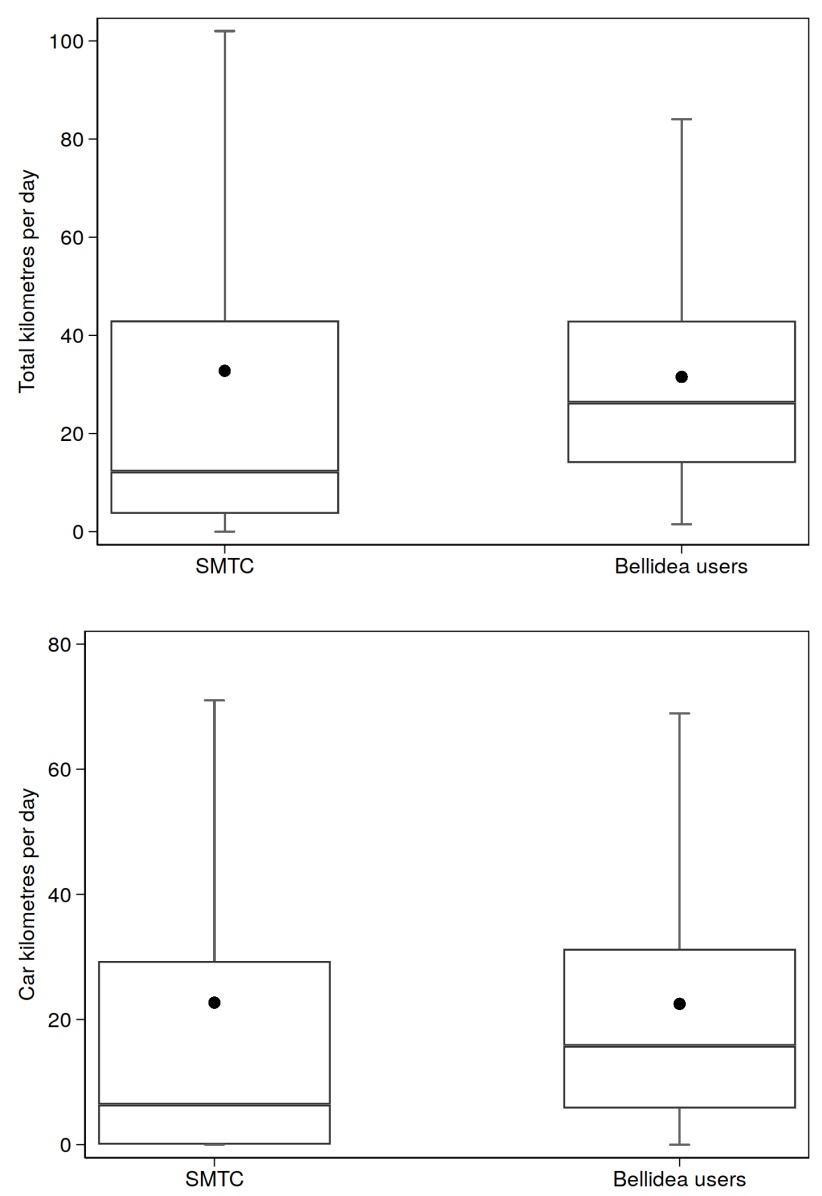

Figure 5: Box plots with means (filled circles) of mobility data in the 2015 SMTC data available for Bellinzona (left) and mobility baselines for Bellidea users (right)

Table 2

Summary statistics of daily travel distance

\begin{tabular}{lcccccc}
\hline & & \multicolumn{2}{c}{ Total km/day } & & \multicolumn{2}{c}{ Car km/day } \\
\cline { 3 - 4 } \cline { 7 - 7 } & Obs & Mean & SD & & Mean & SD \\
\hline SMTC & 564 & 32.769 & 52.922 & & 22.702 & 38.167 \\
Bellidea users & 207 & 31.533 & 24.091 & & 22.501 & 22.376 \\
\hline
\end{tabular}

tance by car (car kilometers per day, bottom) for the sample from Bellinzona in the 2015 SMTC (left) and for the Bellidea users (right). In the same figure, the respective sample means are indicated with filled circles. The main summary statistics for the two samples (sample sizes, means and standard deviations) are reported in Table $2 .{ }^{4}$

Descriptive statistics hint at the fact that on average Bellidea users travel slightly less kilometers per day than the average people in Bellinzona, both by car and by considering

\footnotetext{
${ }^{4}$ For the sample taken from the 2015 SMTC, we calculate statistics and associated tests by using the sampling weights provided by the Swiss Federal Statistical Office along with the individual survey data (Office fédéral de la statistique, 2018). None of the results actually changes if we do not consider these weights.
}

Table 3

Levene's robust tests for equality of variances and one-tailed two-sample $t$ tests for mean-comparison assuming unequal variances (null hypothesis: mean $\mathrm{km} /$ day in SMTC greater or equal to mean $\mathrm{km} /$ day for Bellidea users)

\begin{tabular}{lccccc}
\hline & \multicolumn{2}{c}{ Total $\mathrm{km} /$ day } & & \multicolumn{2}{c}{ Car km/day } \\
\cline { 2 - 3 } \cline { 6 - 7 } & Statistic & $p$-value & & Statistic & $p$-value \\
\hline Levene's test & 22.66 & 0.000 & & 18.18 & 0.000 \\
test & 0.443 & 0.329 & & 0.090 & 0.464 \\
\hline
\end{tabular}

Table 4

OLS estimates for the mean-comparison between people living in Bellinzona and Bellidea users in daily travel distance controlling for daily travel distance by car

\begin{tabular}{lcc}
\hline & $(\mathrm{I})$ & $(\mathrm{II})$ \\
Dependent variable: & Tot $\mathrm{km} /$ day & Tot $\mathrm{km} /$ day \\
\hline Bellidea user & -0.431 & 1.637 \\
& $(1.664)$ & $(1.456)$ \\
Car km/day & $0.963^{* * *}$ & $0.587^{* * *}$ \\
& $(0.042)$ & $(0.119)$ \\
Car km/day ${ }^{2}$ & & $0.0043^{* *}$ \\
& & $(0.0017)$ \\
Car km/day & & $-8.73 \mathrm{e}-06^{* *}$ \\
& & $(3.74 \mathrm{e}-06)$ \\
Constant & $10.287^{* * *}$ & $12.920^{* * *}$ \\
& $(1.925)$ & $(2.268)$ \\
\hline Observations & 771 & 771 \\
R-squared & 0.535 & 0.544 \\
\hline Breusch-Pagan test & 0.071 & 0.075 \\
RESET test & 0.002 & 0.487 \\
\hline
\end{tabular}

Heteroskedasticity-robust standard errors in parenthesis. For Breusch-Pagan tests $\left(\mathrm{H}_{0}\right.$ : regression disturbances are i.i.d.) and Ramsey RESET tests $\left(\mathrm{H}_{0}\right.$ : model is not misspecified), $p$-values reported. Significance levels: ${ }^{*} 10 \%,{ }^{* *} 5 \%,{ }^{* * *} 1 \%$.

all transport means. This notwithstanding, such differences are small and never statistically significant, as shown by the one-tailed two-sample $t$ tests for mean-comparison reported in Table 3.

We test the null that on average Bellidea users do not travel more kilometers per day than people living in Bellinzona (both in total and by car) assuming unequal variances. Indeed, in the Levene's robust tests we reject the null of equality of variances at the $0.1 \%$ significance level and the lower variance of the distribution of kilometers per day for Bellidea users compared to the SMTC mobility data is to be expected, since the latter are single-day mobility data whereas the former are individual averages over a twoweek period. Although none of the distributions is normal (the Shapiro-Wilk tests for normality always reject the null of normality at the $0.1 \%$ significance level), the $t$ tests are asymptotically valid and both samples are rather large.

We also compare the average daily travel distance between people living in Bellinzona (2015 SMTC sample) and Bellidea users conditional on the daily travel distance by car, 
Table 5

Baseline mobility of Bellidea users and length of app use: OLS estimates

\begin{tabular}{lcccc}
\hline & $(\mathrm{I})$ & $(\mathrm{II})$ & $(\mathrm{III})$ & $(\mathrm{IV})$ \\
Dep. var. (km/day): & Total & Car & Total & Car/Total \% \\
\hline Active weeks & $0.838^{*}$ & 0.319 & $0.529^{* * *}$ & -0.390 \\
& $(0.459)$ & $(0.429)$ & $(0.195)$ & $(0.558)$ \\
Car km/day & & & $0.969^{* * *}$ & \\
& & & $(0.032)$ & \\
Constant & $25.235^{* * *}$ & $20.106^{* * *}$ & $5.751^{* * *}$ & $68.400^{* * *}$ \\
& $(3.831)$ & $(3.582)$ & $(1.745)$ & $(4.660)$ \\
\hline Observations & 207 & 207 & 207 & 207 \\
R-squared & 0.016 & 0.003 & 0.824 & 0.002 \\
\hline Breusch-Pagan test & 0.135 & 0.080 & 0.600 & 0.743 \\
RESET test & 0.529 & 0.608 & 0.556 & 0.910
\end{tabular}

Standard errors in parenthesis. For Breusch-Pagan tests $\left(\mathrm{H}_{0}\right.$ : regression disturbances are i.i.d.) and Ramsey RESET tests $\left(\mathrm{H}_{0}\right.$ : model is not misspecified), $p$-values reported.

Significance levels: $* 10 \%, * * 5 \%,{ }^{* *} 1 \%$

by regressing the total kilometers per day traveled by each individual in the overall sample $(n=564+207=771)$ on the kilometers per day traveled by car and on a dummy taking value 1 if the individual is a Bellidea user and 0 otherwise. Results are shown in Table 4, which reports both a model with the plain regressor 'car km/day' (column I) and a model with the quadratic and cubic forms of the same regressor (column II), which are introduced in order to avoid functional misspecification problems revealed by the Ramsey RESET test on model I. In both cases, the coefficient attached to the dummy, which estimates the difference in the conditional means, is not statistically significant at the $10 \%$ level. Therefore, there is no evidence of a self-selection bias.

In order to estimate the attrition bias, we consider the baseline mobility of Bellidea users and study if there is evidence of any mean dependence between baseline mobility and the number of weeks users actively use the app. In particular, we investigate if the expected baseline travel distance (total and by car) of app users depends on the duration of the period of app use, measured in terms of weeks; that is, whether the 'loyal' app users, who interacted with the app for a greater number of weeks, have baseline mobility patterns (kilometers per week, both in total and by car) systematically different from the 'early dropout' app users, who interacted with the app for a smaller number of weeks. If so, the phenomenon of attrition could bias the estimates of the actual impact of the app in empirical analyses that do not properly account for it.

As it is apparent in Figure 6, which shows the box plots with means of the overall daily travel distance (top) and the daily travel distance by car (bottom) of app users over their number of active weeks, there is no strong, clear evidence of such a dependency. Indeed, the slope coefficients in the simple OLS regressions of kilometers per day (total and by car) on the number of active weeks are not statistically significant
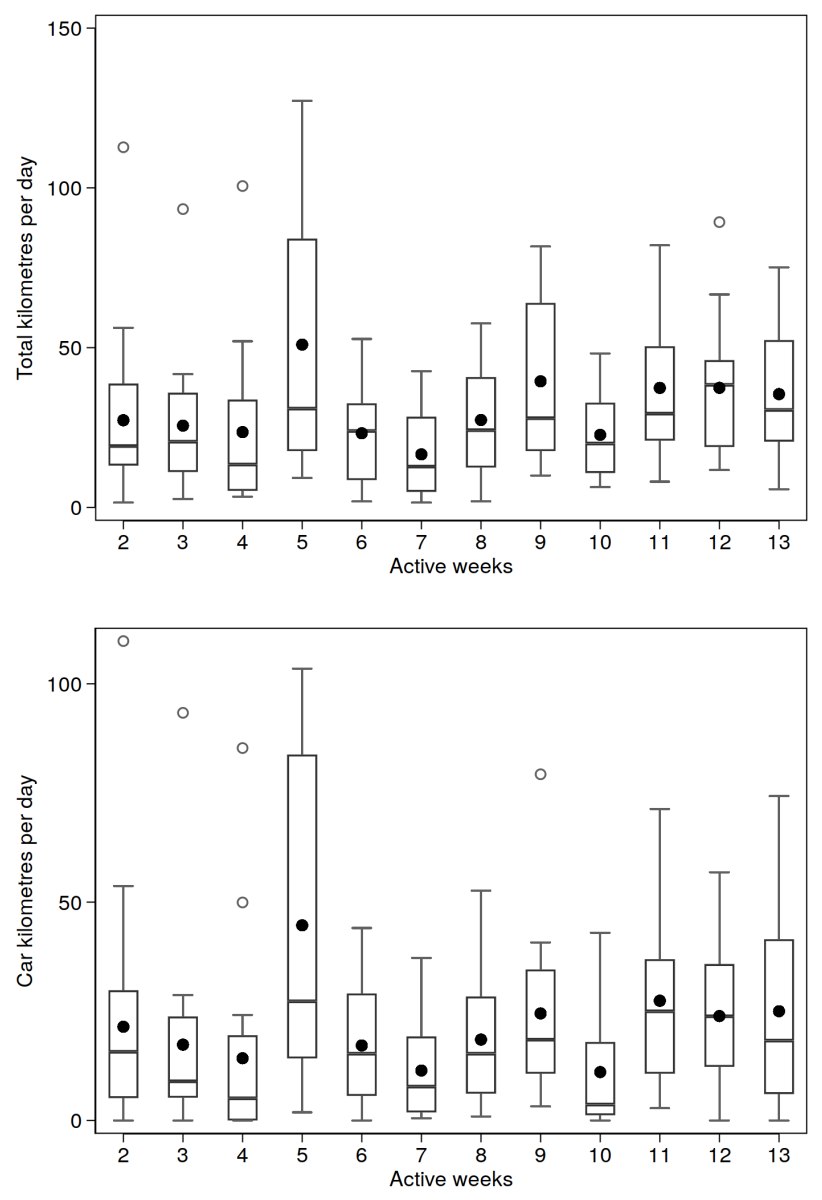

Figure 6: Box plots with means (filled circles) of mobility baselines of Bellidea users over the number of active weeks: total daily travel distance and daily travel distance by car

at the 5\% level (Table 5, columns I and II). ${ }^{5}$

In fact, although not statistically significant at the 5\% level, the point estimates of both the coefficients are positive and, for total kilometers per day, the coefficient is statistically significant at the $10 \%$ level. Thus, there seems to be mild evidence that those who remained loyal to the app for more weeks are characterized by longer overall daily travel distances than those who dropped out app use earlier. Does this provide evidence of an attrition bias, though in the opposite direction than what one might reasonably expect? Namely, are 'loyal' app users characterized by less sustainable mobility patterns than 'early dropout' users?

As a matter of fact, if we run the multiple regression of the overall daily travel distance on the number of active weeks and the daily travel distance by car (column III of Table 5), the resulting OLS estimates show that the partial correlation between the total kilometers per day and the number of weeks of app use, controlling for the average distance traveled daily by car, is positive and statistically significant

\footnotetext{
${ }^{5}$ There is no evidence of misspecification (nonlinearities not accounted in the model), as shown by the Ramsey RESET tests (which use the powers of the fitted values).
} 
at the $1 \%$ level. Thus, given the same distance by car, 'loyal' app users travel slightly more. Furthermore, these users also travel slightly more by car, since the regression coefficient attached to the daily travel distance by car, statistically significant at the $1 \%$ level, is also positive. This therefore confirms a mild evidence of attrition bias. Particularly, 'loyal' app users appear to be characterized by less sustainable mobility patterns than 'early dropout' app users, since they travel slightly more kilometers per day overall and also by car.

Rather than showing that Bellidea addresses the 'already converted', the mild bias that we find goes in the opposite direction, that is, the app is used longer by those who move more and therefore have less sustainable patterns.

To disentangle the nature of this slight distortion, we calculate the ratio of the distance traveled by car to the total traveled distance. In this way, it is possible to check if the slightly greater mobility of the loyal users is due to a greater use of the car, which would therefore make them more "car dependent' compared to their peers abandoning the app. Using this ratio as the dependent variable, statistical significance disappears: in the simple regression of the percentage of distance traveled by car on the number of active weeks, in fact, the slope coefficient turns out to be not statistically significant, negative and rather close to zero (column IV of Table 5). This additional analysis allows us to conclude that the most loyal users do not have a proportionally different car use compared to the other users of the app but are simply covering slightly higher distances on a daily basis, with car use growing accordingly.

To summarize, the case of the Bellidea intervention provides no evidence of self-selection bias: in spite of the optin, voluntary, self-selection framework, the Bellidea app managed to attract the interest by the 'mainstream car drivers' representing the average people of Bellinzona. Regarding attrition, instead, there is a mild evidence of a bias when baselines are defined in terms of car and total travel distances: user retention appears to be slightly dependent on the user's baseline mobility patterns. Remarkably, however, such a dependency would suggest that Bellidea has a potentially higher behavioral change impact than the one estimated without properly accounting for attrition biases in empirical analysis that cannot control for individual unobserved heterogeneity. In fact, 'loyal' app users appeared to be closer to the app's actual target group, since they travel slightly more daily distances, both in total and by car. Furthermore, when mobility baselines are defined as percentage of travel kilometers by car, the evidence of such a bias disappears.

\section{Discussion}

In this section, the previous results are briefly commented on. First, we address the significant difference between the number of app subscribers and users. Secondly, we discuss the overall reliability of baseline mobility data and the possible sources of measurement or specification error. Finally, we discuss the possibility for generalization to other con- texts, and suggest possible venues of further research.

As for the first issue, it is worth reminding that, as shown in Figure 4, the number of individuals who registered an account on the Bellidea app but then quit its use before the end of the validation period (two weeks) is quite high: 514 individuals over a total of 721 registered accounts. This means that the large majority of app subscribers (71\%) have not even started to explore the specific app features. Although we have no data to be referred to, this phenomenon could be attributed to two concurrent factors. On the one hand, the general trend towards a 'high-speed' (Rosa, 2010), 'McDonaldized' society (Ritzer, 2014), together with smartphones' overabundant media stimulation, could have quickly shifted users' attention (Liebherr et al., 2020): users install the app, quickly scan its features, realize that its use does not provide them with immediate and direct benefits, and quite fast forget about it, being ready to focus their attention elsewhere. On the other hand, a quick disaffection towards app use might also be due to poor performances of its mobility tracking features, coupled with the burden of providing validations. During the training phase, in fact, the app accuracy in transport mode detection might have been lower, and users might have judged it as unsatisfactory. Furthermore, they might have been disappointed by the validation effort requested by the app and, by thinking that validations were always needed during app use (which might have actually happened, since there was no obligation for app users to read in details the tutorial and FAQ information provided with the app itself), they might have decided to drop. In this case, the possibility of future rewards by the Bellidea prizes (cinema tickets, entrance to swimming pool and tennis club, tourism cable car experiences, locally produced honey) might have been assessed as not enough to motivate to retain app use. To test these hypotheses, future research may account for a survey targeting all Bellidea registered users, coupled with a few in-depth interviews with a selection of them. Enriching the quantitative approach with qualitative insights coming from the interviews would help to shed light on the very early app churn phenomenon, suggesting possible measures to decrease attrition, to the benefit of future implementations.

As for the second issue (measurement error), the baselines considered throughout this analysis may not be fully reliable for at least three reasons. First, they are based on a short observation period. This means that they might not necessarily encompass the variety of mobility needs people face during their life. Nevertheless, two weeks are longer than the single-week baseline that is usually considered to assess the effectiveness of voluntary behavior change programs (Stopher et al., 2009), as well as than the single-day mobility data collection in the SMTC (Office fédéral de la statistique, 2018), even though in the latter the single day duration of tracking is compensated by a larger sample.

Secondly, Bellidea baselines may not be reliable for the data collection method. While relying on automatically collected data via smartphone apps allows to avoid errors in information retrieval and recording that may affect surveys or interviews, $100 \%$ accuracy cannot be taken for granted. It is 
in fact sufficient for the app to fail to record travel trips that users, in good faith, forget their phone at home, the phone is off (e.g. for it runs out of battery), or the GPS is disabled. That said, it is worth stressing that, as far as the estimation of the self-selection bias via the comparison with the mobility data taken from the SMTC is concerned, since these measurement errors decrease the observed baseline mobility of the app users, they would lead to overestimate the bias. This notwithstanding, we find no evidence of the bias. As regards the analysis of attrition, instead what is actually necessary and sufficient for the measurement errors to bias the estimates is that there are systematic differences in their magnitude between 'loyal users' and 'early dropout users'. In this respect, note that in a scenario of highly increased battery consumption due to GPS tracking, users who more frequently disable the GPS tracking might be more prone to dropping-out earlier, since they are less satisfied with the app performance. If so, the mobility baselines collected for such early dropout users would be lower than they really are, which might weaken the obtained findings, since the actual differences in the mobility baselines between 'early dropout' and 'loyal' users would be actually lower than observed.

Thirdly, wrong baseline data might be due to users on purpose cheating the system when validating trips, either due to a Hawthorne effect or because they hope that, by wrongly training the system (e.g., by leading it consider car-based trips as active mobility ones), they may have easier access to prizes. The Hawthorne effect is however unlikely to have happened in the case of Bellidea, since app users were never told their data would have been analyzed within a research project and in any case anonymity was strictly guaranteed regarding any possible use made by the city of Bellinzona on the collected data. Furthermore, the detailed app mechanics were not publicly disclosed, although admittedly discussed in the living-lab meetings; thus, it is not likely that the majority of users understood that providing wrong validations of their trips during the training phase could help them to collect more points (and thus prizes) later on, with the persuasive app features enabled.

Leveraging progress in automated transport mode detection, future app-based behavior change interventions may reduce the need for manual user validation of the transport mode, thus overcoming possible cheating activities of users. If so, such interventions may also allow for longer baseline collection periods, since users are not requested for daily interactions with the app to validate their trips. However, the benefits produced by an extension of the baseline period would need to be carefully weighted against the risk of increased app churn, since the collection of baseline mobility data would in any case necessarily require that the app persuasive features were not enabled.

Finally, we cannot exclude that our findings are affected by specification error. In fact, we on purpose chose to characterize individual mobility patterns by referring to the 'overall travel distance' and 'travel distance by car' variables, then averaged at the daily level. Choosing to characterize the baselines through additional mobility variables, e.g. by also including the daily travel distance by active mobility or public transport, or through different mobility variables, such as the number of daily routes or activities by transport mode, or the daily travel time by transport mode, might have led to different results. Future research comparing the results varying the selected variables to characterize the mobility baselines would therefore be relevant for confirming our findings.

As for the question if the current findings about the Bellidea app can be generalized to other contexts, and possibly to other persuasive apps as well, caution would definitely be needed in providing an affirmative answer. A number of contextual factors might in fact have led some Bellidea users to keep using the app, while leading other Bellidea users to stop using it. For instance, the average presence of a high quality public transport or the topography of the city of Bellinzona, characterized by wide flat areas, might have favored retention of 'mainstream car driver' users, while in cities where alternatives to car use are less available or less efficient, 'mainstream car drivers' might have been led to drop using the app earlier, due to the lack of perceived alternatives to car use. Therefore, replicating the Bellidea transition experiment in a number of cities would be needed to confirm current findings and conclude they still hold in different areas and contexts. Furthermore, also the cultural framework in the city of Bellinzona might have played a role, particularly regarding the shared meanings associated to mobility practices. ${ }^{6}$ From this point of view, the fact that the Bellidea app was part of a wider transition experiment, which included a co-design living lab process aimed at publicly engaging the local community of Bellinzona towards more sustainable mobility patterns, might have supported the creation of shared meanings in favor of public transport and active mobility and against car use. Finally, the specific features of the Bellidea app might have also played a role in favoring long-term retention of 'mainstream car driver' users, compared to other similar persuasive apps in the mobility domain, which provides a further warning against the external validity of the current findings. For instance, the choice of relying on 'external regulation' motivational factors, such as prizes, as the majority of behavior change apps in the mobility domain are doing, might only have had a short-term role in retaining the interest of mainstream car drivers in the region of Bellinzona, if they did not regard prizes as sufficiently interesting, compared to their standard of living. This is supported by Habibipour et al. (2016), who found that building a long-term commitment between an ICT-based system and its users requires a proper economic reward or by Tsirimpa et al. (2019), who found that, while in general reward-based schemes can be effective in promoting multi-modal mobility choices, as the age increases, more intense behavior changes require higher rewards. ${ }^{7}$ In-

\footnotetext{
${ }^{6}$ Following the social practice theory as it was conceptualized by (Shove et al., 2012), 'materials' (e.g., equipment or infrastructure), 'competences' (e.g., skills and know-how), and 'meanings' (e.g., images, symbols and social norms), affecting and reinforcing the mobility practices in Bellinzona, might have influenced the Bellidea app users in their decision about keeping to use the app.

${ }^{7}$ This is not in contrast with the motivation crowding theory (Frey and
} 
stead, the specific choice of directly involving potential app users in the co-design of its persuasive features within the Bellidea living lab might have helped to better respond to the users' needs, desires and expectations. In particular, since mainstream car drivers were actively engaged in the living lab co-creation process, the resulting app features and contents might have been more attractive for their peers, with the effect of increasing their intrinsic motivation towards app use, compared with apps developed under more traditional expert-driven approaches.

\section{Conclusion}

In this paper, a transition experiment aimed at favoring a reduction in car use at the urban level was presented and discussed. The intervention, which was run in the Swiss city of Bellinzona (Canton Ticino, Italian-speaking part of Switzerland) and was given the name of Bellidea, consisted in a living lab process aimed at creating a persuasive smartphone app, followed by a 13-week long period during which such an app was made freely available to any interested citizen either living, working or studying in the city.

We have analyzed the Bellidea intervention with the aim of assessing the presence and extent of possible self-selection and attrition biases directly stemming from the voluntary, opt-in, self-selection framework underlying use of such persuasive apps. Finding evidence of such biases would imply that any assessment of the impact without a strict RCT would result in biased estimates, thus leading to over- or underestimate its actual behavior change impact. Considering the number of barriers that preclude the use of RCTs in such a domain, investigating these issues has therefore direct and practical relevance for policy-making purposes.

To this aim, we have analyzed the mobility characteristics of the users of the Bellidea app as they result from their mobility baselines (total daily travel kilometers and daily kilometers traveled by car), i.e. data collected through the app itself during the first two weeks of app use, when no persuasive features were enabled. We have tested if, according to such baselines, app users could be best described as 'mainstream car drivers', corresponding to the population of Bellinzona, or to 'converted' individuals, having reduced car use in favor of public transport and active mobility - both when they start using the app and over time, along the 13 weeks of the Bellidea intervention. The identification of statistically significant differences would in fact imply presence of self-selection and attrition biases, posing critical challenges for any statistical analyses aimed at assessing the behavior change impact.

The comparison with the mobility data for the people living in Bellinzona from the 2015 Swiss Mobility and Transport Census (SMTC) has provided no evidence of a selfselection bias: in spite of the opt-in self-selection framework, we have found no statistically significant differences between Bellidea users and the reference population, neither

Jegen, 2001), since monetary rewards would mostly appeal to individuals with no or very limited prior intrinsic motivation to change. considering mean daily total travel distances nor considering mean daily travel distances by car. Furthermore, we have found no strong evidence of an attrition bias that characterizes app use over time: despite a remarkable drop-out rate, we only found a mild evidence of statistically significant differences in the mobility baselines of the Bellidea app users, conditionally on the number of weeks they actively interacted with the app. However, such evidence goes into the opposite direction than one could reasonably expect. In fact, there is no evidence of 'preaching to the converted' who have already adopted sustainable mobility patterns. Depending on the definition of 'sustainable' mobility baselines, average baseline mobility patterns of Bellidea 'loyal' users are in fact either as sustainable as those by 'mainstream car drivers' or even less sustainable than them. Therefore, we have concluded that the Bellidea app managed to attract and retain over time the interest by its actual target groups and that any analyses of its behavior change impact that are not performed through strict RCTs would not be at risk of overestimating its impact.

Such findings provide us with additional insights relevant for local policy-makers and suggest venues for future research. On the one hand, by indicating that the Bellidea app managed to reach and retain its target group of users, they strengthen earlier research findings showing promising behavior change impacts by persuasive apps in the mobility domain and suggest to perform additional research and investments in this field. The case of Bellidea in fact allows us to exclude that, as a consequence of the self-selection framework, it mostly reached 'already converted' users of public transport and active mobility. In such a case, its behavior change potential would have been largely constrained, as well as its overall role and relevance within sustainability processes and transition to a low-carbon economy. Neglected by its actual target group, if anything it would in fact result in improvements of mobility patterns of individuals already oriented to sustainable mobility, with limited scope for further improvements. The lack of self-selection and attrition biases suggest this was not the case.

Of course, analyzing whether possible changes in mobility behavior are maintained over time is crucial in order to confirm the long lasting behavior change effectiveness of the intervention and the lack of relapse to previous behavior. Therefore, we recommend future research to also explore the long-term effect of the intervention, well after its conclusion.

Data collected in the Bellidea intervention indicate also another venue for further research: even though the selfselection framework does not produce selection and critical attrition biases, the number of observed app users is definitely limited. Thus, future research should further investigate the reasons for the interest in the app - and, conversely, the reasons for the lack of interest by the large majority of the population. This is crucial to understand whether devoting additional efforts and resources for app-based persuasion in the mobility field is overall worthwhile and capable of producing a tangible impact at the city level. In this respect, it is important to explore the role of community-building ac- 
tivities, such as the co-creation process run in the Bellidea living lab and transition experiment, as well as the role of tangible prizes.

Designing interventions that span over longer periods of time would allow to understand if, following a typical process of diffusion of innovation, the number of app users significantly increases over time. Only gaining these information will allow to understand if upscaling the app's impact at the city level is possible, and how to do it, in order to effectively tackle the challenge of the transition to a more sustainable, low-carbon mobility.

Finally, evidence about the actual behavior change impacts of the app would allow to perform comparisons with other (soft) policy tools aimed at mobility behavior change, thus further supporting urban decision-makers in the challenge of implementing effective mobility policies in the context of scarce resources which characterizes public policymaking.

\section{CRediT authorship contribution statement}

Francesca Cellina: Conceptualization, Methodology, Validation, Investigation, Resources, Data curation, Writing - original draft, Visualization. Giuseppe Vittucci Marzetti: Methodology, Formal analysis, Writing - review \& editing, Visualization. Marco Gui: Supervision, Writing - review \& editing.

\section{Declaration of competing interest}

Francesca Cellina was personally involved in the Bellidea transition experiment, by designing the intervention and running the living lab, in partnership with the City of Bellinzona. The Bellidea transition experiment was supported by the City of Bellinzona, by the Swiss Federal Office of Energy (SFOE) under the ERA-NET scheme and by the Innosuisse - Swiss Innovation Agency within the Swiss Competence Center for Energy Research (SCCER) Mobility.

\section{Acknowledgments}

The authors gratefully acknowledge Pasquale Granato, Roman Rudel and Josè Simão at ISAAC-SUPSI for their support, as well as the citizens who participated with enthusiasm to the Bellidea living lab and interacted with the Bellidea app. The authors are also thankful to two anonymous reviewers for the insightful comments on a previous version of this paper. The usual caveats apply.

\section{References}

Ajzen, I., 1991. The theory of planned behavior. Organizational Behavior and Human Decision Processes 50, 179-211. doi:10.1016/0749-5978(91) 90020-T.

Almirall, E., Lee, M., Wareham, J., 2012. Mapping living labs in the landscape of innovation methodologies. Technology innovation management review 2, 12-18. doi:10.22215/timreview/603.

Amel, E., Manning, C., Scott, B., Koger, S., 2017. Beyond the roots of human inaction: fostering collective effort toward ecosystem conservation. Science 356, 275-279. doi:10.1126/science. aal1931.
Anagnostopoulou, E., Bothos, E., Magoutas, B., Schrammel, J., Mentzas, G., 2018. Persuasive technologies for sustainable mobility: State of the art and emerging trends. Sustainability 10, 2128. doi:10.3390/ su10072128.

Andersson, A., Hiselius, L.W., Adell, E., 2018. Promoting sustainable travel behaviour through the use of smartphone applications: A review and development of a conceptual model. Travel Behaviour and Society 11, 52-61. doi:10.1016/j.tbs.2017.12.008.

Arnott, B., Rehackova, L., Errington, L., Sniehotta, F.F., Roberts, J., Araujo-Soares, V., 2014. Efficacy of behavioural interventions for transport behaviour change: systematic review, meta-analysis and intervention coding. International Journal of Behavioral Nutrition and Physical Activity 11, 133. doi:10.1186/s12966-014-0133-9.

Bamberg, S., 2013. Changing environmentally harmful behaviors: A stage model of self-regulated behavioral change. Journal of Environmental Psychology 34, 151-159. doi:10.1016/j. jenvp. 2013.01.002.

Bamberg, S., Fujii, S., Friman, M., Gärling, T., 2011. Behaviour theory and soft transport policy measures. Transport policy 18, 228-235. doi:10. 1016/j. tranpol.2010.08.006.

Banister, D., 2008. The sustainable mobility paradigm. Transport policy 15, 73-80. doi:10.1016/j.tranpol.2007.10.005.

Bhushan, N., Steg, L., Albers, C., 2018. Studying the effects of intervention programmes on household energy saving behaviours using graphical causal models. Energy Research \& Social Science 45, 75-80. doi:10.1016/j.erss.2018.07.027.

Bie, J., Bijlsma, M., Broll, G., Cao, H., Hjalmarsson, A., Hodgson, F., Holleis, P., van Houten, Y., Jacobs, K., Koolwaaij, J., et al., 2012. Move better with tripzoom. International Journal on Advances in Life Sciences 4, 125-135.

Bonsall, P., 2009. Do we know whether personal travel planning really works? Transport Policy 16, 306-314. doi:10.1016/j.tranpol.2009.10. 002.

Van den Bosch, S., 2010. Transition experiments: exploring societal changes towards sustainability. Ph.D. thesis. University of Rotterdam.

Bothos, E., Mentzas, G., Prost, S., Schrammel, J., Röderer, K., 2014. Watch your emissions: Persuasive strategies and choice architecture for sustainable decisions in urban mobility. PsychNology Journal 12.

Bowden, H., Hellen, G., 2019. A data driven, segmentation approach to real world travel behaviour change, using incentives and gamification, in: Müller, B., Meyer, G. (Eds.), Towards User-Centric Transport in Europe. Springer, pp. 173-182. doi:10.1007/978-3-319-99756-8_12.

Bucher, D., Mangili, F., Cellina, F., Bonesana, C., Jonietz, D., Raubal, M., 2019. From location tracking to personalized eco-feedback: A framework for geographic information collection, processing and visualization to promote sustainable mobility behaviors. Travel behaviour and society 14, 43-56. doi:10.1016/j. tbs. 2018.09.005.

Cairns, S., Harmer, C., Hopkin, J., Skippon, S., 2014. Sociological perspectives on travel and mobilities: A review. Transportation research part A: policy and practice 63, 107-117. doi:10.1016/j.tra.2014.01.010.

Cairns, S., Sloman, L., Newson, C., Anable, J., Kirkbride, A., Goodwin, P., 2008. Smarter choices: assessing the potential to achieve traffic reduction using 'soft measures'. Transport Reviews 28, 593-618. doi:10.1080/01441640801892504.

Campos-Sánchez, F.S., Valenzuela-Montes, L.M., Abarca-Álvarez, F.J., 2019. Evidence of green areas, cycle infrastructure and attractive destinations working together in development on urban cycling. Sustainability 11, 4730. doi:10.3390/su11174730.

Cellina, F., Bucher, D., Mangili, F., Veiga Simão, J., Rudel, R., Raubal, M., 2019. A large scale, app-based behaviour change experiment persuading sustainable mobility patterns: methods, results and lessons learnt. Sustainability 11, 2674. doi:10.3390/su11092674.

Cellina, F., Castri, R., Simão, J.V., Granato, P., 2020. Co-creating appbased policy measures for mobility behavior change: A trigger for novel governance practices at the urban level. Sustainable Cities and Society 53, 101911. doi:10.1016/j.scs.2019.101911.

Chatterjee, K., Bonsall, P., 2009. Special issue on evaluation of programmes promoting voluntary change in travel behavior. Transport Policy 16. 
Cocchia, A., 2014. Smart and digital city: A systematic literature review, in: Dameri, R.P., Rosenthal-Sabroux, C. (Eds.), Smart city. Springer, pp. 13-43. doi:10.1007/978-3-319-06160-3.

Deci, E.L., Ryan, R.M., 2008. Self-determination theory: a macrotheory of human motivation, development, and health. Canadian psychology/Psychologie canadienne 49, 182-185. doi:10.1037/a0012801.

Dell'Era, C., Landoni, P., 2014. Living lab: A methodology between usercentred design and participatory design. Creativity and Innovation Management 23, 137-154. doi:10.1111/caim.12061.

Deterding, S., Dixon, D., Khaled, R., Nacke, L., 2011. From game design elements to gamefulness: defining gamification., in: Proceedings of the 15th international academic mindtrek conference: envisioning future media environments, Tampere, Finland, ACM Press, New York, NY.. pp. 9-15.

Di Dio, S., La Gennusa, M., Peri, G., Rizzo, G., Vinci, I., 2018. Involving people in the building up of smart and sustainable cities: How to influence commuters' behaviors through a mobile app game. Sustainable Cities and Society 42, 325-336. doi:10.1016/j.scs.2018.07.021.

Fogg, B.J., 1998. Persuasive computers: perspectives and research directions, in: Proceedings of the SIGCHI conference on human factors in computing systems, pp. 225-232.

Fogg, B.J., 2003. Persuasive Technology. Using Computers to Change What We Think and Do. Morgan Kaufmann, Amsterdam. doi:10.1016/ B978-1-55860-643-2. X5000-8.

Frey, B.S., Jegen, R., 2001. Motivation crowding theory. Journal of economic surveys 15, 589-611. doi:10.1111/1467-6419.00150.

Froehlich, J., Dillahunt, T., Klasnja, P., Mankoff, J., Consolvo, S., Harrison, B., Landay, J.A., 2009. Ubigreen: investigating a mobile tool for tracking and supporting green transportation habits, in: Proceedings of the SIGCHI Conference on Human Factors in Computing Systems, ACM. pp. 1043-1052.

Gadziński, J., 2018. Perspectives of the use of smartphones in travel behaviour studies: Findings from a literature review and a pilot study. Transportation Research Part C: Emerging Technologies 88, 74-86.

Gillespie, R., 1991. Manufacturing knowledge: a history of the Hawthorne experiments. Cambridge University Press, Cambridge.

Gössling, S., 2018. ICT and transport behavior: A conceptual review. International Journal of Sustainable Transportation 12, 153-164. doi:10. 1080/15568318.2017.1338318.

Graham-Rowe, E., Skippon, S., Gardner, B., Abraham, C., 2011. Can we reduce car use and, if so, how? A review of available evidence. Transportation Research Part A: Policy and Practice 45, 401-418. doi:10. 1016/j.tra.2011.02.001.

Habibipour, A., Bergvall-Kåreborn, B., Ståhlbröst, A., 2016. How to sustain user engagement over time: A research agenda, in: 22nd Americas Conference on Information Systems: Surfing the IT Innovation Wave, AMCIS 2016, San Diego, United States, 11-14 August 2016.

Hadiji, F., Sifa, R., Drachen, A., Thurau, C., Kersting, K., Bauckhage, C., 2014. Predicting player churn in the wild, in: 2014 IEEE Conference on Computational Intelligence and Games, Ieee. pp. 1-8.

Hamari, J., 2017. Do badges increase user activity? a field experiment on the effects of gamification. Computers in Human Behavior 71, 469-478. doi:10.1016/j.chb.2015.03.036.

Hamari, J., Huotari, K., Tolvanen, J., 2015. Gamification and economics, in: Walz, S.P., Deterding, S. (Eds.), The gameful world: Approaches, issues, applications. MIT Press., Cambridge, MA, pp. 139-161.

Hamari, J., Koivisto, J., Pakkanen, T., 2014. Do persuasive technologies persuade? A review of empirical studies, in: Spagnolli, A., Chittaro, L., Gamberini, L. (Eds.), Persuasive Technology - Persuasive, Motivating, Empowering Videogames. Springer, pp. 118-136.

Hausman, J.A., Wise, D.A., 1979. Attrition bias in experimental and panel data: the Gary income maintenance experiment. Econometrica 47, 455473. doi: $10.2307 / 1914193$.

Heckman, J.J., 1990. Selection bias and self-selection, in: Eatwell, J., Milgate, M., Newman, P. (Eds.), Econometrics. Palgrave Macmillan, London, pp. 201-224. doi:10.1007/978-1-349-20570-7_29.

Holden, E., Banister, D., Gössling, S., Gilpin, G., Linnerud, K., 2020. Grand narratives for sustainable mobility: A conceptual review. Energy
Research \& Social Science 65, 101454. doi:10.1016/j. erss.2020.101454. Hu, X., Zhu, X., Chiu, Y.C., Tang, Q., 2020. Will information and incentive affect traveler's day-to-day departure time decisions?-An empirical study of decision making evolution process. International Journal of Sustainable Transportation 14, 403-412. doi:10.1080/15568318. 2019. 1570402.

Huang, B., Thomas, T., Groenewolt, B., Fioreze, T., van Berkum, E.J., 2018. The effect of incentives to promote cycling: a mobility living lab, in: Proceedings of the 97th Annual Meeting Transportation Research Board.

Jariyasunant, J., Abou-Zeid, M., Carrel, A., Ekambaram, V., Gaker, D., Sengupta, R., Walker, J.L., 2015. Quantified traveler: Travel feedback meets the cloud to change behavior. Journal of Intelligent Transportation Systems 19, 109-124. doi:10.1080/15472450.2013.856714.

Jylhä, A., Nurmi, P., Sirén, M., Hemminki, S., Jacucci, G., 2013. Matkahupi: a persuasive mobile application for sustainable mobility, in: Proceedings of the 2013 ACM conference on Pervasive and ubiquitous computing adjunct publication, pp. 227-230.

Kazhamiakin, R., Loria, E., Marconi, A., Scanagatta, M., 2021. A gamification platform to analyze and influence citizens' daily transportation choices. IEEE Transactions on Intelligent Transportation Systems 22, 2153-2167.

Liebherr, M., Schubert, P., Antons, S., Montag, C., Brand, M., 2020. Smartphones and attention, curse or blessing? -A review on the effects of smartphone usage on attention, inhibition, and working memory. Computers in Human Behavior Reports 1, 100005. doi:10.1016/j. chbr. 2020. 100005.

Luederitz, C., Schäpke, N., Wiek, A., Lang, D.J., Bergmann, M., Bos, J.J., Burch, S., Davies, A., Evans, J., König, A., Farrelly, M.A., Forrest, N., Frantzeskaki, N., Gibson, R.B., Kay, B., Loorbach, D., McCormick, K., Parodi, O., Rauschmayer, F., Schneidewind, U., Stauffacher, M., Stelzer, F., Trencher, G., Venjakob, J., Vergragt, P.J., von Wehrden, H., Westley, F.R., 2017. Learning through evaluation - A tentative evaluative scheme for sustainability transition experiments. Journal of Cleaner Production 169, 61-76. doi:10.1016/j. jclepro. 2016.09.005.

Manville, C., Cochrane, G., Cave, J., Millard, J., Pederson, J.K., Thaarup, R.K., Liebe, A., Wissner, M., Massink, R., Kotterink, B., 2014. Mapping smart cities in the EU. Technical Report. Directorate General for Internal Policies, European Parliament.

Mattioli, G., Roberts, C., Steinberger, J.K., Brown, A., 2020. The political economy of car dependence: A systems of provision approach. Energy Research \& Social Science 66, 101486. doi:10.1016/j. erss. 2020.101486.

Neirotti, P., De Marco, A., Cagliano, A.C., Mangano, G., Scorrano, F., 2014. Current trends in smart city initiatives: Some stylised facts. Cities 38, 25-36. doi:10.1016/j.cities.2013.12.010.

Nevens, F., Frantzeskaki, N., Gorissen, L., Loorbach, D., 2013. Urban transition labs: co-creating transformative action for sustainable cities. Journal of Cleaner Production 50, 111-122. doi:10.1016/j . jclepro. 2012.12. 001.

Newman, P., Kenworthy, J., 1999. Sustainability and cities: overcoming automobile dependence. Island press, Washington, D.C.

O'Brien, K., 2015. Political agency: the key to tackling climate change. Science 350, 1170-1171. doi:10.1126/science. aad0267.

Office fédéral de la statistique, 2017. Comportement de la population en matière de transports: Résultats de microrecensement mobilité et transports 2015. Technical Report. OFS Neuchâtel.

Office fédéral de la statistique, 2018. Microrecensement mobilité et transports 2015 - Rapport méthodologique: plan d'échantillonage, taux de réponse et pondération. Technical Report. OFS Neuchâtel.

Oinas-Kukkonen, H., 2013. A foundation for the study of behavior change support systems. Personal and Ubiquitous Computing 17, 1223-1235. doi:10.1007/s00779-012-0591-5.

Pallot, M., Trousse, B., Senach, B., Scapin, D., 2010. Living lab research landscape: From user centred design and user experience towards user cocreation, in: First European Summer School "Living Labs", Inria (ICT Usage Lab), Userlab, EsoceNet, Universcience, Paris, France.

Pangbourne, K., Bennett, S., Baker, A., 2020. Persuasion profiles to promote pedestrianism: Effective targeting of active travel messages. Travel 
Behaviour and Society 20, 300-312. doi:10.1016/j.tbs.2020.04.004.

Periáñez, Á., Saas, A., Guitart, A., Magne, C., 2016. Churn prediction in mobile social games: Towards a complete assessment using survival ensembles, in: 2016 IEEE International Conference on Data Science and Advanced Analytics (DSAA), IEEE. pp. 564-573.

Piras, F., Sottile, E., Calli, D., Meloni, I., 2018. Automatic data collection for detecting travel behavior: the IPET platform. Procedia computer science 134, 421-426. doi:10.1016/j. procs. 2018.07.189.

Prochaska, J.O., Velicer, W.F., 1997. The transtheoretical model of health behavior change. American Journal of Health Promotion 12, 38-48. doi:10.4278/0890-1171-12.1.38.

Reed, M.S., Graves, A., Dandy, N., Posthumus, H., Hubacek, K., Morris, J., Prell, C., Quinn, C.H., Stringer, L.C., 2009. Who's in and why? A typology of stakeholder analysis methods for natural resource management. Journal of Environmental Management 90, 1933-1949. doi:10.1016/j. jenvman. 2009.01.001.

Ritzer, G., 2014. The McDonaldization of society. Sage, London.

Rosa, H., 2010. High-speed society: Social acceleration, power, and modernity. Pennsylvania State University Press, Pennsylvania.

Ryan, R.M., Deci, E.L., 2000. Intrinsic and extrinsic motivations: Classic definitions and new directions. Contemporary Educational Psychology 25, 54-67. doi:10.1006/ceps.1999.1020.

Sanders, E.B.N., 2002. From user-centered to participatory design approaches, in: Frascara, J. (Ed.), Design and the social sciences. CRC Press, pp. 18-25. doi:10.1201/9780203301302.ch1.

Sanders, E.B.N., Stappers, P.J., 2008. Co-creation and the new landscapes of design. CoDesign 4, 5-18. doi:10.1080/15710880701875068.

Schwartz, S.H., 1977. Normative influences on altruism, in: Berkowitz, L. (Ed.), Advances in Experimental Social Psychology. Elsevier, Amsterdam. volume 10, pp. 221-279.

Schwartz, S.H., Howard, J.A., 1981. A normative decision-making model of altruism, in: Rushton, J.P., Sorrentino, R.M. (Eds.), Altruism and helping behavior: Social, personality, and developmental perspective. Erlbaum, Hillsdale, N.J., pp. 189-211.

Sengers, F., Wieczorek, A.J., Raven, R., 2019. Experimenting for sustainability transitions: A systematic literature review. Technological Forecasting and Social Change 145, 153-164. doi:10.1016/j. techfore. 2016. 08.031.

Shaheen, S., Cohen, A., Martin, E., 2017. Smartphone app evolution and early understanding from a multimodal app user survey, in: Meyer, G., Shaheen, S. (Eds.), Disrupting Mobility. Lecture Notes in Mobility. Springer, Cham, pp. 149-164. doi:https://doi.org/10.1007/ 978-3-319-51602-8_10.

Shaheen, S., Cohen, A., Zohdy, I., Kock, B., 2016. Smartphone applications to influence travel choices: practices and policies. Technical Report. U.S. Department of Transportation, Federal Highway Administration.

Shove, E., 2010. Beyond the ABC: climate change policy and theories of social change. Environment and planning A 42, 1273-1285. doi:10. 1068/a42282.

Shove, E., Pantzar, M., Watson, M., 2012. The dynamics of social practice: Everyday life and how it changes. Sage, London.

Silva, B.N., Khan, M., Han, K., 2018. Towards sustainable smart cities: A review of trends, architectures, components, and open challenges in smart cities. Sustainable Cities and Society 38,697-713. doi:10.1016/ j.scs.2018.01.053.

Steg, L., Tertoolen, G., 1999. Sustainable transport policy: the contribution from behavioural scientists. Public money and management 19, 63-69. doi:10.1111/1467-9302.00154.

Stopher, P., Clifford, E., Swann, N., Zhang, Y., 2009. Evaluating voluntary travel behaviour change: Suggested guidelines and case studies. Transport Policy 16, 315-324. doi:10.1016/j. tranpol.2009.10.007.

Sunio, V., Schmöcker, J.D., 2017. Can we promote sustainable travel behavior through mobile apps? Evaluation and review of evidence. International Journal of Sustainable Transportation 11, 553-566. doi:10. 1080/15568318.2017.1300716.

Sunstein, C.R., 2014. Nudging: a very short guide. Journal of Consumer Policy 37, 583-588. doi:10.1007/s10603-014-9273-1.

di Teulada, B.S., Meloni, I., 2016. Individual persuasive eco-travel technol- ogy, a mobile persuasive application for implementing voluntary travel behaviour change programmes. IET Intelligent Transport Systems 10, 237-243.

Tiefenbeck, V., Wörner, A., Schöb, S., Fleisch, E., Staake, T., 2019. Realtime feedback promotes energy conservation in the absence of volunteer selection bias and monetary incentives. Nature Energy 4, 35-41. doi:10. 1038/s41560-018-0282-1.

Tsirimpa, A., Polydoropoulou, A., Pagoni, I., Tsouros, I., 2019. A rewardbased instrument for promoting multimodality. Transportation research part F: traffic psychology and behaviour 65, 121-140. doi:10.1016/j. trf. 2019.07.002.

Urry, J., 2004. The 'system' of automobility. Theory, Culture \& Society 21, 25-39. doi:10.1177/0263276404046059.

Vlahogianni, E.I., Barmpounakis, E.N., 2017. Gamification and sustainable mobility: Challenges and opportunities in a changing transportation landscape, in: Hussein, D. (Ed.), Low Carbon Mobility for Future Cities: Principles and Applications. Institution of Engineering and Technology (IET), p. 277.

Vlassenroot, S., Gillis, D., Bellens, R., Gautama, S., 2015. The use of smartphone applications in the collection of travel behaviour data. International Journal of Intelligent Transportation Systems Research 13, $17-27$.

Weber, J., Azad, M., Riggs, W., Cherry, C.R., 2018. The convergence of smartphone apps, gamification and competition to increase cycling. Transportation research part F: traffic psychology and behaviour 56, 333-343.

Welsh, B., Baird, T., Zhao, J., Block-Schachter, D., 2014. Web app design to implement travel behavioral nudging using "moves", in: Proceedings of the Transportation Research Board 93rd Annual Meeting, Washington DC, United States, 12-16 January 2014.

Wemyss, D., Castri, R., Cellina, F., De Luca, V., Lobsiger-Kägi, E., Carabias, V., 2018. Examining community-level collaborative vs. competitive approaches to enhance household electricity-saving behavior. Energy Efficiency 11, 2057-2075. doi:10.1007/s12053-018-9691-z.

Zhao, J., Baird, T., 2014. 'Nudging' active travel: A framework for behavioral interventions using mobile technology, in: Proceedings of the Transportation Research Board 93rd Annual Meeting, Washington DC, United States, 12-16 January 2014. 